\title{
A GEOGRAFIA ESCOLAR BRASILEIRA: UMA REVISÃO NECESSÁRIA
}

\author{
Rosimeire Petruci \\ Universidade Federal de Uberlândia - UFU \\ Programa de Pós-Graduação em Geografia \\ meirepetrucci@hotmail.com
}

Rita de Cássia Martins de Souza

Universidade Federal de Uberlândia - UFU

Instituto de Geografia, Uberlândia - MG

ritacmsou@gmail.com

\begin{abstract}
RESUMO
Revisitar a história da Geografia escolar coloca em evidência os momentos importantes pela qual a ciência geográfica caminhou desde sua sistematização no final do século XIX até a segunda metade do século XX, após sua consolidação definitiva no rol das ciências humanas. Essas evidências refletem o papel desempenhado pela Geografia no Brasil e o complexo jogo de interesses que permearam a história brasileira desde tempos remotos na intenção de estabelecer um modelo de nacionalidade com aspiração progressista e moderna. Este artigo tem o intuito de sinalizar algumas reflexões sobre como o pensamento geográfico serviu de escopo para a consolidação da Geografia como disciplina escolar em consonância com os interesses das classes dominantes na busca por um "ideal de brasilidade". Não é por acaso que veremos, a seguir, como a Geografia escolar se concretizou como ferramenta necessária para a (re)organização do território brasileiro, tanto no campo ideológico quanto na prática.
\end{abstract}

Palavras-chave: Pensamento Geográfico. Geografia Escolar. História da Geografia. Identidade Nacional.

\section{BRAZILIAN GEOGRAPHY IN SCHOOL: THE NEED OF REVISION}

\begin{abstract}
Back over the story of Geography in school highlights decisive moments in which the geographical science passed by its since systematization in the late nineteenth century to the second half of the twentieth century, after its definitive consolidation in the role of the humanities. This evidence makes clear the role filled by Geography in the complex interplay of interests that permeate Brazilian history since ancient times in an attempt to establish a model of citizenship with progressive and modern aspiration. This paper aims to identify some reflections on how the Geographic Thought became to the consolidation scope of the Geography as a School Subject in line with the interests of the dominant classes in the search for an "ideal Brazilianness". It is not by chance that we will see, next, how school geography has become a necessary tool for the (re) organization of Brazilian territory, both in the ideological field and in practice.
\end{abstract}

Keywords: Geographical Thought. School geography. History of Geography. National Identity.

\section{INTRODUÇÃO}

A consolidação da educação brasileira como prática do saber começou a ganhar forma no século XVI ainda no processo de formação do Brasil Colônia. Embora rudimentar e incipiente, a educação trazida pelos padres Jesuítas mesclava interesses religiosos juntamente com a necessidade de conhecimento. O saber geográfico, ainda deficiente e sem concretude, 
aparecia nos relatos de viagens feitos por cientistas europeus sobre os elementos paisagísticos como a botânica, zoologia e a mineralogia que, à época, despertavam os interesses das sociedades científicas europeias. A incipiente geografia ainda sem conotação científica logo alcançara espaço nas primeiras instituições escolares marcadas pelo caráter meramente descritivo e mnemônico.

Nos períodos que se seguiram, as mudanças na geografia escolar acompanharam as transformações no cenário político, econômico e cultural da época. Com a vinda da Família Real em 1808 e posteriormente com a Independência do Brasil em 1822, as preocupações em torno da construção de uma Nação subserviente, moderna e letrada movimentaram as elites da época, desejosos pelo refinamento de um povo sem instrução intelectual. Neste se sentido, a Geografia ensinada nos colégios serviu como direcionamento para o fortalecimento do nacionalismo brasileiro que se consolidava fora das algemas de Portugal rumo à construção de uma nação moderna e progressista. Destarte, os discursos geográficos proferidos à época possibilitaram a difusão do conhecimento de maneira geral, sobretudo no tocante à construção de uma identidade e de uma unidade nacional ${ }^{1}$ (ANSELMO, 2000; MORAES, 2002), com o intuito de exaltar a construção da nacionalidade e de um espírito de pertencimento patriótico com a Nação. Afinal, não seria possível unificar um território se a ideologia do "amor à pátria e ao progresso" não fosse, de alguma maneira, repercutida.

Tendo por base essas premissas que nortearam a consolidação da geografia escolar, a proposta desse artigo vem no sentido de refletir sobre a construção dessa disciplina, não apenas como um componente curricular, mas, também, com o intuito de apresentar elementos que fizeram da Geografia escolar uma condicionante basilar para a formação territorial brasileira. A temática justifica-se, portanto, tendo em vista a necessidade de se compreender 0 papel delegado a Geografia que, para além do campo acadêmico científico, apresenta grande importância em diferentes áreas de aplicação no campo do conhecimento.

A metodologia utilizada para orientar essas reflexões está ancorada em revisões bibliográficas referendadas por estudiosos alinhados às pesquisas sobre a História da Geografia e a História do Pensamento Geográfico. A revisão dessa literatura específica possibilita uma maior compreensão sobre a evolução do ensino de Geografia, no sentido de promover a difusão de um pensamento que, desde os primórdios da colonização do país, serviu como norte para a construção de um ideal de brasilidade, responsável pela efetivação da unidade e da identidade nacional brasileira. Nesse sentido, buscou-se analisar como o pensamento geográfico presente no âmbito escolar e expresso nos compêndios ${ }^{2}$ e nos livros didáticos -, influenciaram na construção de uma identidade nacional significativamente difundida no século XIX, sobretudo na primeira metade do século XX.

\section{AS ORIGENS DA GEOGRAFIA ESCOLAR E A CONSTRUÇÃO DO SABER GEOGRÁFICO}

A história da Geografia como disciplina escolar há muito antecede a criação do ensino superior no Brasil haja vista que suas contribuições podem ser atreladas ao surgimento da educação brasileira quando da chegada das primeiras missões jesuíticas que aqui se instalaram em 1549. A presença dos padres jesuítas na Colônia estava diretamente ligada à ideia de "educar" os índios e os colonos que aqui viviam sob a égide do padre Manuel da Nóbrega e, posteriormente, José de Anchieta. A pedagogia vigente no primeiro século da colonização brasileira colocada em prática pelos jesuítas estava diretamente ligada à concepção tradicional religiosa, isto é, à filosofia da educação católica ajustada às condições particulares da colônia (SOUZA; PEZZATO, 2010).

\footnotetext{
1 Os conceitos de Identidade e Unidade Nacional foram apresentados por Anselmo (2000) e Moraes (2000) e compõem o conjunto de análises e interpretações sobre a Formação Territorial Brasileira.

${ }^{2}$ Os compêndios podem ser entendidos como um conjunto de sínteses ou ideias teóricas. “Os compêndios sinalizam um momento histórico, uma teoria, uma ciência, características ou particularidades" (Dicionário Aurélio online).
} 
Face aos estudos orientados pelas missões, despontavam também nesse período, contribuições de cunho geográfico que podem ser observados em ensaios literários produzidos à época; destes alguns tratavam de temas que se consagraram como temas geográficos. Poucos eram os trabalhos que possuíam, de fato, um caráter científico, e que podiam ser verificados nos estudos de "cientistas que faziam expedições pelo país e traziam descrições sobre diversos aspectos dos lugares visitados. Até então, esses conhecimentos chegavam aos colégios apenas de forma esparsa como parte dos estudos de literatura" (SOUZA; PEZZATO, 2010, p. 77).

Com o fim das escolas jesuíticas em função das Reformas Pombalinas de 1759 foram criadas disciplinas que substituíram aquelas anteriormente ofertadas nos colégios jesuítas. Apesar das mudanças inerentes aos novos métodos de ensino organizados e aplicados pelo Marquês de Pombal, o conhecimento geográfico:

\begin{abstract}
[...] ainda era restrito a instituições públicas e a exploradores, chegando às escolas apenas imagens vagas do que seria o território brasileiro. Em decorrência da vinda de muitos "cientistas" europeus ao Brasil, começou a haver algumas mudanças na produção de conhecimento geográfico no país. Mesmo que esparsos e sem objetivo metodológico e científico, a maior parte desses trabalhos era realizada para satisfazer os interesses do Estado (SOUZA; PEZZATO, 2010, p. 78).
\end{abstract}

É importante enfatizar a influência que Sebastião José de Carvalho e Melo - o Marquês de Pombal - exerceu na história da educação brasileira no contexto colonial da época e que, não obstante, delineou os rumos do ensino nessas paragens.

A 1a Reforma Educacional promovida por Pombal dá-se em detrimento da expulsão da Companhia de Jesus, sobretudo pela necessidade de promover um novo modelo educacional que não se limitasse apenas ao doutrinamento religioso e à mera aplicação da escrita e da leitura. Este fato está diretamente associado aos desdobramentos econômicos e políticos que eclodiram na sociedade portuguesa em meados do século XVIII e que, respaldados pelas Reformas Pombalinas, serviram como estratégias para a modernização dos domínios territoriais portugueses na busca pela continuidade, assegurando assim o regime absolutista.

Embora houvesse por parte do Marquês uma necessidade de se colocar em prática um conhecimento de cunho científico na intenção de suprimir o pensamento religioso difundido pelos jesuítas e, embora considerando a influência do iluminismo na Europa do século XVIII,

Pombal não pode ser considerado um defensor do mesmo, pelo menos não do iluminismo que pregava a autonomia. Ao contrário, como estadista que era, considerava as ideias (sic) iluministas dos demais países da Europa perigosas à autoridade real. Não obstante, sentia a necessidade de colocar Portugal a altura das demais nações esclarecidas da época, mas sobre o controle de um forte poder centralizador. (SECO; AMARAL, 2006, p. 4).

A reforma educacional promovida por Pombal representou apenas uma das mudanças substanciais que eclodiram no período colonial. O surgimento de um "espírito de nacionalidade" refletia as intenções de uma elite local que se consolidava paulatinamente em consonância com diversos acontecimentos.

A Inconfidência Mineira no final do século XVIII simbolizou o descontentamento em relação à exploração do governo português que inibia o desenvolvimento industrial e comercial do Brasil. Almejavam, os Inconfidentes, instituir a independência brasileira, liberar a comercialização de manufaturas fortalecendo o mercado interno, além de criar uma universidade pública na cidade de Vila Rica.

Em 1808, com a chegada da Corte portuguesa, o território brasileiro passou por mudanças significativas no que se refere ao contexto político, econômico e social. Fazia-se necessário promover uma ressignificação do território buscando atender às novas exigências advindas da Família Real, sobretudo a mudança da condição de Colônia para Reino Unido de Portugal e Algarves. 
Foram criadas [nesse período] instituições de caráter técnico e científico, tais como as escolas de Cirurgia da Bahia e de Anatomia e Cirurgia do Rio de Janeiro - ambas em 1808 -, as academias dos Guardas-Marinhas (1808) e Real Militar (1810), além do Real Horto (1808) e do Museu Real (1818), estes últimos sediados na capital do Império (NAGAMINI, 2004, p. 137).

Ressalta-se com Nagamini (2004) que a importância dada às atividades técnicas e científicas no transcorrer do século XIX teve como expoente a ascensão do capitalismo industrial. Foi, por tanto, através do crescimento econômico e do acúmulo de capital que se percebeu a necessidade de estimular a organização de escolas profissionais, cursos superiores e, posteriormente, a criação de universidades, além de outros centros propagadores de conhecimento.

Não seria exagero dizer que as primeiras providências estabelecidas por $\mathrm{D}$. João $\mathrm{VI}$ foram ao encontro das necessidades proeminentes da Colônia. Era de interesse e urgente no momento formar profissionais necessários à formação do Estado e à elite local, como advogados, engenheiros e médicos.

As transformações em todas as esferas foram ocorrendo, porém sem rupturas significativas. A Proclamação da Independência em 1822 por D. Pedro I obrigou a recente Nação a estabelecer novas legislações que norteariam o desenvolvimento do país. Assim, em 1823 ficou estabelecida a nova Constituição votada em Assembleia Constituinte. O debate acalorado perpassou por diferentes temas, sendo a instrução educacional uma das questões centrais.

$O$ reinado de $D$. Pedro II seguiu de maneira semelhante a seus antecessores. A preocupação com a educação e com o "refinamento" do povo brasileiro permaneceu latente. A criação de escolas de formação profissional prevaleceu durante a Primeira República (1889 - 1930) e serviu como única ferramenta necessária para a formação de profissionais liberais.

O desenvolvimento da técnica e da ciência, que se intensificaram ao longo do século XIX, começaram por romper com os velhos resquícios da "incipiente" Colônia. A modernidade almejada pela pequena elite começa a fazer ruir as arcaicas estruturas dando lugar a novas formas de organização econômica, social e cultural, imprescindíveis a realização do progresso.

Sobre o aprimoramento da educação e da ciência Nagamini (2004) sinaliza que as expedições científicas estrangeiras que se dirigiram para o Brasil após a elevação da categoria de Reino Unido ao de Portugal e Algarves em 1815, resultaram do reestabelecimento das relações diplomáticas entre Portugal e as metrópoles europeias, permitindo o acesso de missões científicas em terras brasileiras.

Os trabalhos dos viajantes europeus realizados sobre o Brasil encontraram maior difusão ao longo do século XIX e pode-se dizer que os mesmos marcaram os diversos movimentos em prol da criação de escolas de ensino secundário. Cabe ressaltar que esses movimentos desempenhavam uma finalidade junto à construção dos interesses vinculados ao Estado que se consolidava naquele momento. Nesse sentido, os debates que permeavam as discussões acerca da consolidação dos colégios centravam-se em torno de várias correntes de pensamento, sobretudo no Positivismo, no Liberalismo e no Cientificismo, dando corpo às manifestações que se consolidavam no período, centrado no poder e no estabelecimento de um método científico como instrumento necessário à difusão do conhecimento.

O século XIX marca não só o triunfo do liberalismo europeu, ligado ao direito natural, que considera a natureza humana como base da própria lei natural, cuja única realidade é a liberdade do homem; marca também o triunfo do cientificismo, que reconhece uma só natureza material, que engloba e explica o mundo dos valores e o mundo dos fatos. (RIBEIRO JÚNIOR, 2006, p. 11).

A profusão desses acontecimentos não marcou somente o velho continente, mas também, movimentaram a elite brasileira da época exigindo, inclusive, um novo padrão de educação que contemplasse um método de ensino diferenciado, juntamente com a formação de professores. Segundo Rocha (1996), é por intermédio dessas novas instituições escolares criadas no século XIX que o saber geográfico irá se destinar a propagar conceitos que serão apreendidos por influência das experiências advindas do estudo das ciências exatas e naturais, refletindo o 
pensamento positivista. Dessa forma, pode-se depreender que a geografia escolar do século XIX enquadrava-se nos princípios dessa ciência "mensurável", sendo o homem considerado um elemento da natureza.

Rocha (1996) chama à atenção quanto à aplicação dessa disciplina no contexto escolar da época, afirmando que os conhecimentos geográficos se destinavam a dar apenas um panorama geral para os alunos, ou seja, uma Geografia com um teor particularmente descritivo e exato, em uníssono com o saber "tradicional".

Os currículos plenamente tradicionais descrevem o espaço geográfico. Um espaço criado a partir das premissas positivistas de neutralidade e objetividade, espaço esse que é uma abstração e, portanto não retrata a realidade. Possui intocadas, uma quantidade determinada de rios, tantos habitantes e esses parecem levitar por sobre o quadro físico. Um espaço geográfico que é apolítico por questões políticas (CARVALHO, 1998, p. 29, apud HERCULANO, 2011, p. 20).

A finalidade em se compreender os aspectos naturais regionais vinha ao encontro da necessidade de despertar o nacionalismo patriótico (VLACH, 1984) atrelada à construção de uma identidade nacional (ANSELMO, 2000). O pensamento geográfico durante o Império no Brasil tinha uma ligação estreita com o poder político, e isto se refletia na maneira como o saber geográfico era difundido nas escolas (HERCULANO, 2011).

Gerida a partir de obras didáticas, a Geografia da época baseava-se em uma síntese de ideias fundamentadas pelos professores que, aplicados aos alunos, tinham o intuito de difundir os saberes sistemáticos. Várias sínteses de Geografia foram publicadas no período oitocentista e foram de fundamental importância para o conhecimento da Geografia enquanto disciplina escolar.

Essas sínteses revelavam uma instrução teórico-metodológica reduzida apenas ao domínio da descrição e da aparência dos fenômenos. Grande parte de suas informações estavam respaldadas sobre a geografia dos lugares: localização das montanhas, a natureza do solo, a classificação dos povos segundo suas diferenças físicas, etc.

O Compendio Elementar de Geographia Geral e Especial do Brasil, obra específica do intelectual oitocentista Thomaz Pompeu de Souza Brasil foi largamente difundida no Segundo Império. Adotado como livro de referência no Colégio Pedro II e nos demais Liceus teve sua aprovação pelo Instituto Histórico e Geográfico Brasileiro - IHGB para ser utilizado como parte dos estudos relacionados à Geografia do Brasil.

\begin{abstract}
O compendio didático mais difundido no Império Brasileiro deve ter tido uma certa importância, que não era meramente scientifica, mas parece-nos tinha um forte viés político. A Geografia que as elites deveriam aprender, e foi a que aprenderam ou memorizaram, durante muitas décadas dos oitocentos, era aquela que, colocada aos currículos, formava aquela plêiade de homens bons que, em último caso, em um país de negros escravos, mestiços sem posses e índios selvagens, eram os únicos brasileiros que dos lados de cá efetivamente havia (SOUSA NETO, 2000, p. 30).
\end{abstract}

Não por acaso que os compêndios didáticos do Império Brasileiro foram determinantes para o ensino de Geografia. Neles estavam apregoados os ideais nacionalistas e patrióticos que eram transmitidos pelos professores, além de atuarem no campo intelectual, moral e na formação dos docentes e alunos. Vivia o Brasil um momento de formação de uma identidade nacional necessária para a consolidação de um "novo" país livre das algemas do colonialismo. "A escola, para os poucos que nela puderam ingressar, foi a possibilidade de criar uma elite extremamente ciosa de sua condição europeia, branca, ilustrada" (SOUSA NETO, 2000, p. 3132).

A Independência brasileira representou muito mais que uma ruptura econômica e cultural de uma sociedade colonial. Esta pode ser entendida como um dos processos gerados entre as classes dominantes locais e regionais que lideravam as esferas políticas e econômicas no período. Destarte, o processo de independência foi determinante para a consolidação das 
classes dominantes no cenário nacional deslindando, inclusive, durante o percurso histórico, os desdobramentos da ocupação do território e de que forma foram "pensadas" e ocupadas as diferentes áreas.

Os discursos acalorados em prol da defesa da Nação e, consequentemente, de um espírito de nacionalidade foram responsáveis pelo desenvolvimento de uma nova concepção de sociedade brasileira através da elaboração de projetos e modelos de nação necessários entre os membros dessas classes em particular. Não obstante, o pensamento geográfico no Império tinha uma relação forte com o poder político e tal prestígio tinha desdobramentos diretos na forma de fazer circular o saber geográfico nas escolas. Esse fato não é exclusivo do século XIX uma vez que, desde a antiguidade, a Geografia tem relações diretas com o Estado já que o conhecimento do lugar implicava no estabelecimento de estratégias de dominação do espaço e de expansão territorial.

No caso do Brasil, antiga colônia portuguesa, país de capitalismo tardio, parece-nos que era preciso soldar o território indispensável às barganhas feitas pela elite nacional em âmbito mundial e, pari passu, manter o pequeno círculo dessa elite cidadã, brasileira e nacionalista, logo excludente, dentro do mesmo processo que a fazia parte do mundo, desejosa de civilização, francesa nos trópicos, uma ilha de letrados em meio ao mar de analfabetos (SOUZA NETO, 2000, p. 38).

Cabe destacar que uma das primeiras produções de relevante importância no âmbito geográfico e, posteriormente, acolhida pela pequena elite letrada foi a obra do padre Manuel Aires de Casal intitulada "Corografia Brasílica"; um compêndio geográfico que exerceu grande influência entre os professores de Geografia. Publicado pela Imprensa Régia em 1817, o então "geógrafo" e "historiador" Casal dedicou-se aos estudos da Corografia do Brasil sendo sua obra escrita sob as bases de uma geografia mnemônica, alicerçada basicamente em descrições e inventários.

A emancipação do território brasileiro por intermédio da Proclamação da Independência em 1822 promoveu um fortalecimento da economia mercantil escravocrata em decorrência do crescimento da produção cafeeira instalada na porção leste do país (hoje região sudeste), mais precisamente nos estados de São Paulo e Rio de Janeiro. Estas e outras mudanças foram determinantes para o reordenamento do território e para a configuração de novas paisagens.

Nessa fase do Império destacaram-se algumas obras geográficas que serviram de aporte para conhecer e explorar o território. A metodologia empregada nesses trabalhos consistia na observação e na descrição dando ênfase aos aspectos físicos e naturais. As expedições científicas promovidas por Auguste de Saint-Hilaire, Pierre Delalande, entre outros membros do Museu de História Natural de Paris percorreram São Paulo, Rio de Janeiro, Minas Gerais, Santa Catarina, Espírito Santo, Rio Grande do Sul e Goiás entre os anos de 1816 e 1822. Dessas observações científicas surgiram trabalhos como a "Flora Brasiliae e Meridionales", de Saint-Hilaire, além de relatos como "Viagem à Província de São Paulo e Resumos das Viagens ao Brasil", "Províncias Cisplatinas e Missões do Paraguai" (NAGAMINI, 2004).

As atividades científicas empreendidas por esses viajantes foram de grande valia para a exploração e o conhecimento do território brasileiro ainda em fase de descobrimento. Embora essas obras não fossem propriamente de caráter geográfico, elas cumpriram um papel fundamental para os estudos de botânica, etnologia, geologia, mineralogia e zoologia. Os resultados desses estudos eram apresentados de maneira simplificada nas escolas, focados, minimamente, na descrição e memorização.

A consolidação, de fato, da Geografia como componente curricular ocorreu em 1837, quando esse conhecimento foi introduzido nos programas escolares oficiais. Nesse contexto, "já então era claro que os saberes geográficos também seriam norteadores na formação do cidadão, sobretudo daqueles que estariam à frente dos interesses da economia, do Estado, da cultura" (SILVA, 2012, p. 291-292). Nesse mesmo período a Geografia adquiri corpo e status de ciência através das primeiras sistematizações feitas por Humboldt e Ritter na Alemanha, pioneiros na construção de uma Geografia Moderna, de conteúdo tradicional. 
Importante destacar que a sistematização da Geografia se dá em meio à eclosão dos conflitos políticos, econômicos e sociais da Alemanha diante da necessidade da constituição de um Estado nacional, imprescindível para o desenvolvimento alemão. Moraes (2005) afirma que o avanço das relações capitalistas, sobretudo o expansionismo napoleônico, despertou nas classes dominantes alemãs a ideia de unificação nacional. A junção de todos esses elementos caros à Geografia conferiu ao discurso geográfico uma relevância especial.

Temas como domínio e organização do espaço, apropriação do território, variação regional, entre outroș, estarão na ordem do dia na prática da sociedade alemã de então. É, sem dúvida, deles que se alimentará a sistematização geográfica. Do mesmo modo como a Sociologia aparece na França, onde a questão central era a organização social (um país em que a luta de classes atingia um radicalismo único), a Geografia surge na Alemanha onde a questão do espaço era primordial (MORAES, 2005, p. 15-16).

Ainda por dentro do processo de sistematização da Geografia, merecem destaque as formulações de Friedrich Ratzel que, no final do século XIX, publica obras que muito diz sobre a constituição do Estado nacional alemão. "A Geografia de Ratzel foi um instrumento poderoso de legitimação dos desígnios expansionistas do Estado alemão recém-constituído" (MORAES, 2005 , p. 18). Nesse contexto, Ratzel irá se destacar como um intelectual, tendo seus trabalhos voltados para a construção do projeto estatal fortemente arraigado ao discurso imperialista. Em 1882, a publicação de seu principal livro Antropogeografia - Fundamentos da aplicação da Geografia à História estampa o surgimento da Geografia Humana (MORAES, 2005). Segundo Ratzel, as condições naturais exercem grande influência sobre a humanidade logo, o meio natural, também atuaria na possibilidade de expansão de um povo influenciando, inclusive, no seu progresso.

O progresso significaria um maior uso dos recursos do meio, logo, uma relação mais íntima com a natureza. Quanto maior o vínculo com o solo, tanto maior seria para a sociedade a necessidade de manter sua posse. É por esta razão que a sociedade cria o Estado (MORAES, 2005, p. 19).

Apesar dos avanços na Geografia proposta por Ratzel que dedicava ao homem um olhar especial, Moraes (2005) é enfático ao dizer que a Geografia Ratzeliana não obteve grandes avanços em termos de método. Continuou cultivando uma geografia respaldada no empirismo, sendo os procedimentos de análise a descrição e a observação.

Um dos desdobramentos das propostas de Ratzel está relacionado com a constituição da Geopolítica, através dos estudos referentes à dominação dos territórios. Essa corrente se estabeleceu a partir das colocações ratzelianas, referente à ação do Estado sobre o espaço (MORAES, 2005). Não por acaso que a difusão do ensino de Geografia nos colégios e liceus brasileiros esteve intimamente ligada à uma perspectiva geopolítica, necessária ao fortalecimento do Estado brasileiro.

No Brasil, o decreto outorgado pela Regência Interina instituiu o Imperial Colégio Dom Pedro II que integrava um projeto civilizatório do qual também fazia parte o IHGB e o Arquivo Público do Império. Inaugurado em 1837, no Rio de Janeiro, o Colégio era frequentado pelos jovens representantes da elite letrada do país, fato este que evidenciava o interesse da classe dominante daquela época.

A intenção dos que foram responsáveis pela criação daquele colégio, não foi apenas dotar a Côrte (sic) de um estabelecimento de ensino secundário mais organizado frente a desordem reinante neste nível de ensino em todo o território do Império. Mais do que isso, objetivaram eles criar uma instituição que servisse de modelo, verdadeiramente padrão de excelência e por que não dizer, paradigma educacional, a ser seguido pelas demais escolas públicas ou particulares existentes ou a serem criadas. (ROCHA, 1996, p. 12).

Claramente, a criação do Colégio Pedro II não se deu de forma espontânea ou por acaso. Desejava-se reestabelecer a ordem na educação, oferecendo à Corte um ensino de qualidade 
na busca pela superação das instruções pombalinas que vigoravam até então. Além disso, a elite brasileira tinha grande interesse na estruturação do ensino médio e favoreceram a implementação junto aos órgãos responsáveis de um modelo educacional e curricular trazidos do exterior.

\begin{abstract}
O Imperial Colégio de Pedro II, que recebera desde sua fundação o "status" de escola padrão, seria alvo da atenção especial do poder central. Criado para ser o "templo do saber oficialmente aceito", o seu funcionamento seria, em consequência, desde o inicio perpassado por alguns preceitos considerados fundamentais por seus fundadores (ROCHA, 1996, p. 2).
\end{abstract}

Não muito diferente do que era proposto na época, segundo Pinheiro (2003), o ensino de Geografia ministrado no Colégio Pedro II no século XIX respaldava-se no exercício da enumeração e descrição de lugares, além de enaltecer o amor à pátria através da exaltação de sua natureza. Isto também é referendado por Rocha sinalizando que,

\begin{abstract}
Ao longo de todo o período imperial, a situação não foi revertida e a geografia escolar permaneceu sob influência do modelo francês. Só eram sentidas alterações no ensino desta disciplina em nossas escolas após estas terem sido implementadas anteriormente naquele país. Avessa a outras influências que não a francesa, permaneceu, hegemonicamente, nossa geografia escolar "bitolada" ao modelo importada até nas primeiras décadas deste século (ROCHA, 1996, p. 3).
\end{abstract}

Como sinalizado anteriormente, a fundação do IHGB foi outro fator que muito representou para a Geografia que se consolidava no momento. A função dessa instituição era reunir e organizar documentos históricos, etnográficos e geográficos que remetessem a história do Brasil.

Algumas mudanças vieram a ocorrer com a Proclamação da República vinculada, sobretudo, à ascensão da classe média, ao contexto do liberalismo econômico crescente no país, ao incipiente processo de industrialização e também de urbanização das cidades acarretando profundas transformações no território e na sociedade brasileira.

No que diz respeito à educação ocorreram várias reformas no ensino, na tentativa de reformular os currículos e o tempo de curso. Embora houvessem iniciativas com o intuito de promover algumas modificações no ensino escolar durante esse período prevalecia na disciplina de Geografia o exercício de repetição e memorização das nomenclaturas, fossem elas relacionadas aos aspectos físicos ou humanos. Segundo Pinheiro (2003), a fragmentação do conhecimento científico do século XIX permeada pela ciência moderna e a divisão social e territorial do trabalho na conjuntura socioeconômica capitalista, produziu um modelo de ensino de Geografia comprometido com a formação do Estado.

\title{
O SÉCULO XX E A EVOLUÇÃO DA GEOGRAFIA ESCOLAR: A CIENTIFICIDADE DOS DISCURSOS SOBRE A IDENTIDADE E A UNIDADE TERRITORIAL.
}

Transitando pelo campo das diversas transformações já sinalizadas, a Geografia escolar do século XX se destacou não apenas pela sua função educativa ou como uma disciplina isolada, mas como saber prático e aplicado, respaldando e fortalecendo inclusive os interesses do Estado. Entretanto, não se deve esquecer que nesse período era produzida no país uma série de obras fundamentais que sustentavam o pensamento geográfico por fora da própria "institucionalização" da Geografia. Obras como "Os Sertões" de Euclides da Cunha, "Caminhos antigos e povoamento do Brasil", de Capistrano de Abreu e "Populações Meridionais do Brasil", de Oliveira Vianna eram de vital importância no sentido de construir o sentido da nacionalidade.

Para alguns autores, a década de 1920 é considerada o início das transformações na Geografia escolar brasileira em direção à Geografia Moderna transformando o modelo tradicional aplicado anteriormente. Nesses anos, inclusive, se constituiu, segundo Anselmo (2000), uma via alemã de Geografia através do Curso Livre Superior de Geografia comandado por Everardo Backheuser e Delgado de Carvalho revelando a influência de Ratzel na institucionalização dessa ciência no Brasil. Esse Curso Livre pode ser entendido como parte do Movimento pela Educação dos anos de 1920. Devem ser destacados também outros 
movimentos que eclodiram nesse período como o Movimento Higienista, a Semana de Arte Moderna e a criação do Partido Comunista.

Admite-se com Anselmo (2000) que a Geografia cumpre um papel de modernização da estrutura social via políticas estatais e via educação. Não é senão outra a razão para a sua atuação junto à criação do Curso Livre de Geografia Superior, em 1926, como já sinalizado anteriormente, através da Sociedade de Geografia do Rio de Janeiro. Dessa forma, entende-se que antes da instalação dos cursos superiores no Brasil já se formavam um clima favorável à institucionalização do curso de Geografia. De modo que Backheuser e Delgado de Carvalho estão entre os maiores estimuladores da Geografia que se instalou no Brasil na década de 1930.

Delgado de Carvalho, Everardo Backheuser e Raja Gabaglia, enquanto professores do Colégio Pedro II modificaram os programas de Geografia dessa instituição servindo, posteriormente, de modelo para todos os colégios brasileiros. Com esses "geógrafos", a Geografia aplicada na escola não deveria dedicar-se apenas ao exercício da descrição e da enumeração, mais que isso: o saber geográfico encontraria respaldo no conhecimento científico.

Responsável por uma produção sistemática de livros didáticos, especialmente voltados para o ensino secundário no Brasil, Delgado de Carvalho publicou, em 1925, a Metodologia do Ensino de Geografia em que propôs que o ensino ocorresse por meio de círculos concêntricos, representando graus sucessivos de complexidade, partindo do conhecido para o desconhecido (CARVALHO, 1990 apud PINHEIRO, 2003).

Formado em Ciências Políticas em Paris e transitando entre diferentes correntes do pensamento social, Delgado de Carvalho dedicou-se aos estudos geográficos no Brasil, preocupando-se em desenvolver uma geografia científica como constava nos moldes europeus. Seguindo esta tendência,

Delgado de Carvalho atua como divulgador das formulações da Escola Geográfica Francesa sem, contudo, abandonar os pressupostos teóricos estabelecidos anteriormente por Ratzel. Esta ambivalência pode ser sentida mais claramente quando sua atenção se volta para temas de geografia política (1929 e 1933), no mesmo momento em que eram escritos os primeiros ensaios de geopolítica no Brasil (MIYAMOTO, 1981, apud, ZUSMAN; PEREIRA, 2000).

Os anos de 1930 marcam, entre outros acontecimentos importantes da história brasileira, a institucionalização da Geografia. O primeiro curso de Geografia foi instalado em 1934 juntamente com a fundação da Universidade de São Paulo. É entre os cursos propostos pela Faculdade de Filosofia Ciências e Letras - FFCL - que a Geografia é institucionalizada no Brasil. Nos anos posteriores à institucionalização, a ligação entre as produções brasileira e francesa eram muito fortes. Pierre Deffontaines e Pierre Mombeig foram os precursores da Geografia institucional no Brasil e também os responsáveis pelo desenvolvimento dessa ciência e seu papel primordial perante o Estado.

A geografia que se instalara com Vidal de La Blache e Jean Brunhes, na França, veio cumprir duas ordens de prioridades no Brasil, mais especificamente da elite paulista interessada na universidade: uma diz respeito à formação liberal, em cujo cerne era adequado ao caráter neutro da ciência; outra, ligada ao levantamento sistemático das características naturais (relevo, vegetação, clima, etc.), e das características humanas. Desta forma, a geografia universitária que se instalava vinha servir de suporte ao conhecimento do território em moldes modernos (ANSELMO, 2000, p.72).

O modelo regional francês aplicado ao ensino de geografia, não apenas na universidade, mas também reproduzido nas escolas, repercutiu algumas transformações no campo teóricometodológico dessa disciplina. No início do século XX a Geografia cunhada por Vidal de La Blache tornou-se referência na produção geográfica mundial. No Brasil, a Geografia escolar seguiu a linha lablachiana, sobretudo no que diz respeito à sistematização dos estudos regionais e das civilizações amplamente difundida nos currículos. 
É comum encontrarmos [nos currículos de Geografia] a divisão de unidades, capítulos e volumes de muitas coleções didáticas, por exemplo, acompanhando os grandes setores das geografias sistemáticas: a geografia física, a geografia humana e a geografia regional. A análise das regiões (do globo, de continentes ou de países) se baseia, por vezes, no esquema natureza-homem-economia (N-H-E), mesclando a fragmentação e a dicotomia homem-natureza, típicas do positivismo, com o método regional lablachiano (SANTOS, 2010, p.7).

A produção nacional de um saber geográfico de modelo francês começou a mostrar seus traços na elaboração dos novos livros didáticos da época. Devidamente orientado por mestres franceses, os geógrafos brasileiros tinham em mãos, de acordo com Santos (1984), todo um aparato metodológico para desenvolver atividades pautadas num conhecimento empírico mais amplo e em moldes mais sistemáticos do território nacional, claramente sustentados nos interesses das classes dominantes envolvidas na construção do poder político do Estado sobre o espaço geográfico nacional.

Com base nesses argumentos, a produção geográfica e didática de Aroldo de Azevedo se destaca na construção de livros didáticos marcados pelas concepções positivistas da Geografia Francesa. Dentre sua produção, cabe sinalizar: "Geografia Geral: Primeira Série Ginasial", "Geografia Regional: de acordo com o programa da Segunda Série do Curso Colegial" e "O Brasil e suas Regiões", todos publicados pela Companhia Editora Nacional.

Os discursos em torno da integração nacional necessários ao próprio projeto de modernização via industrialização tornam-se cada vez mais candentes durante o governo de Getúlio Vargas até culminar no Estado Novo (1937-45) quando a centralização e o fortalecimento do Estado passam a ser disseminados intensivamente, sobretudo através de discursos ideológicos em prol da construção da nacionalidade.

As mudanças no cenário político e econômico continuaram a passos largos entre as décadas de 1960 e 1970. "A revolução tecnoburocrática surgiu ao lado da ideologia do desenvolvimentismo, o qual se faria por meio do planejamento estratégico por técnicos ligados ao aparelho estatal" (PINHEIRO, 2003, p. 25). Cresceu a produção industrial, comemorou-se o milagre brasileiro e como consequência, pagou-se o preço pelo acúmulo da dívida externa.

O período militar instaurado em 1964 provocou mudanças no sistema educacional, principalmente a partir de $1968 \mathrm{com}$ as reformas de base (reforma universitária e a reforma do ensino de $1^{\circ}$ e $2^{\circ}$ graus) outorgadas pelo regime e necessárias para ajustar a educação brasileira com a política vigente. Desenvolveu-se a concepção de que a escola deveria estabelecer uma relação de eficiência entre recursos aplicados e produtividade. Para isso, os conteúdos, os métodos e as técnicas de ensino deveriam ser reformulados. "A intenção era transformar a escola, a fim de torná-la mais eficiente para o desenvolvimento do país" (PINHEIRO, 2003, p. 26). De maneira geral, as concepções liberalistas cederam lugar aos ideais tecnicistas, modificando as propostas pedagógicas e os conteúdos das disciplinas.

Ainda na década de 1960, a disciplina de Estudos Sociais passou a integrar o curso primário, substituindo a História e a Geografia desse currículo. Com inspiração norte americana, esta mudança deixou transparecer a preferência pela orientação técnico-profissional, dando ênfase às ciências exatas e naturais e desqualificando tais disciplinas consideradas "não-técnicas" pelo governo (PINHEIRO, 2003).

Foram muitos os descontentamentos e os prejuízos depositados sobre a Geografia, assim como sobre outras disciplinas, que perderam, por assim dizer, sua identidade. A Geografia aplicada por dentro dos Estudos Sociais perdeu seu caráter estratégico sendo seu conteúdo ministrado de forma fragmentada, excluindo de seu programa o contexto social e o autoritarismo do Estado.

Diversas manifestações de repudio ocorreram por parte de professores e estudantes de Geografia e História nesse período, especialmente nos grandes centros e nas universidades públicas. No entanto, o comportamento do governo autoritário das décadas de 60, 70 e 80, dificultou o debate, utilizando a repressão e a propaganda ideológica para acalmar os descontentamentos e as oposições (PINHEIRO, 2003, p. 30). 
Com o advento das décadas de 1970 e 1980, a ciência geográfica viveu um período de renovação que eclodiu por dentro das diferentes matrizes teóricas do pensamento geográfico. Assim como na academia, a Geografia escolar experimentou o movimento de renovação crítica pautado, sobretudo, nas bases do materialismo histórico-dialético, em oposição à Geografia praticada nos moldes positivistas. "Na realidade, tanto a escola lablachiana quanto as perspectivas positivistas e neopositivistas são vistas como constituidoras de uma Geografia reacionária e burguesa, responsável pelo ocultamento das relações assimétricas de poder presentes na produção do espaço" (SANTOS, 2010, p.8).

Como desdobramento desses movimentos, novas Propostas Curriculares começaram a ser discutidas e reformuladas. Estas propostas foram elaboradas em vários estados do país e seus conteúdos refletiam a conjuntura política de redemocratização nacional. Os processos de ampliação do modo de produção capitalista deram fôlego para as discussões travadas no campo teórico-metodológico da ciência geográfica, inclusive entre professores e outros setores da sociedade.

À guisa de conclusão, a crise da Geografia Tradicional que se instalara a partir de 1970 gerou uma ruptura por parte de muitos geógrafos anteriormente alinhados a esta perspectiva tradicional. O movimento de renovação na Geografia - como ficou conhecido - pautou-se pela busca de novas propostas e por uma liberdade maior de reflexão e criação (MORAES, 2005).

Como exposto brevemente nessa discussão, a construção da Geografia escolar no Brasil seguiu, à rigor, as concepções embasadas pela Geografia Tradicional por ser mnemônica, descritiva e enciclopédica, uma vez que foi sob essas condições que ela se referendou e chegou às escolas. Porém, as críticas em relação ao tradicionalismo da Geografia ganharam força nas escolas e entre os professores brasileiros. As mudanças no modo de produção capitalista, a revolução tecnológica e as necessidades de novos planejamentos para o território foram alguns dos elementos que propiciaram os movimentos a favor do estabelecimento de uma "nova" Geografia.

A realidade do planejamento colocava uma nova função para as ciências humanas: a necessidade de gerar um instrumental de intervenção, enfim uma feição mais tecnológica. A Geografia Tradicional não apontava nessa direção, daí sua defasagem e sua crise (MORAES, 2005, p. 34).

A nova proposta curricular estabelecida para o ensino de Geografia representou um "divisor de águas", principalmente para o movimento de renovação da Geografia Crítica. Seus conteúdos mostravam o espaço geográfico como sendo um espaço social, produzido continuamente pela sociedade. Essas mudanças possibilitaram, mesmo que em longo prazo, uma reestruturação no campo da Geografia escolar na perspectiva de novas abordagens pedagógicas rumo à construção de um currículo comprometido com as questões sócio espaciais, sem perder de vista as necessidades estratégicas impostas pelo Estado na busca pela manutenção da identidade e da unidade territorial.

\section{CONSIDERAÇÕES FINAIS}

Recuperar a história da Geografia escolar é um desafio que se coloca na atualidade, tendo em vista as diferentes orientações teórico-metodológicas presentes na organização dos livros didáticos. Nesse sentido, essas dificuldades estão atreladas ao fato de que os conteúdos dessa disciplina passaram por várias mudanças desde o seu surgimento nos currículos escolares que refletem diretamente à organização socioeconômica brasileira. O aprimoramento da técnica, os avanços científicos em ampla escala somados a modernização dos meios de produção implicaram em transformações profundas na sociedade e, consequentemente, na educação. Sendo a Geografia uma ciência estratégica e que dispõe de disciplinas que atuam diretamente com os fenômenos naturais e sociais, tais implicações aparecem de forma mais contundente alterando de maneira significativa as abordagens geográficas.

Como exposto brevemente ao longo dessa discussão, a Geografia aplicada na escola cumpriu um papel decisivo no contexto brasileiro, sobretudo na formação de uma identidade nacional e na consolidação da unidade territorial. Entre o final do século XIX e nas primeiras décadas do XX a falta de coesão nacional apresentava-se como um entrave às políticas de desenvolvimento do país. Fazia-se necessário dotar o território de estratégias progressistas 
pautadas, principalmente, pelo desenvolvimento de um sentimento de nacionalidade que contribuísse para conhecimento das áreas ainda pouco ou nada exploradas do território. Se essa era a grande discussão do final do XIX, no início do XX em diante a grande preocupação passa a ser de colocar o país frente às nações modernas do mundo. Foi somente no início do século XX que a ideia surtiu efeito no país representando claramente a vitória de grupos progressistas que apontavam na direção de novas opções como a industrialização e a urbanização, só alcançadas definitivamente após os anos de 1930.

A institucionalização da Geografia em 1934 na Universidade de São Paulo - USP influenciou sobremaneira a forma de pensar e fazer Geografia. Destarte, a ciência geográfica - agora reconhecida academicamente no Brasil -, atendeu aos interesses das classes dirigentes brasileiras no sentido de colocar em prática os estudos sobre o território que versavam sobre os aspectos naturais e socioeconômicos. A ocupação efetiva do grande interior brasileiro foi possível, em grande parte, graças aos estudos dessas áreas motivadas pelo exercício científico próprio da Geografia.

O efeito causado pela efetivação da ciência geográfica no Brasil repercutiu nos currículos e na condução do ensino de Geografia nas escolas. Embora os estudos geográficos conservassem o caráter descritivo e mnemônico sobre os lugares, o aprimoramento das análises sobre as diferentes regiões brasileiras e seus diferentes aspectos possibilitaram um sentimento de brasilidade maior de reconhecimento do país, acompanhado do desenvolvimento de um espírito de unidade, bem como de identidade nacional.

Nesses anos, o progresso material e cultural da nação casa-se perfeitamente com as necessidades do mercado interno nacional em que políticas territoriais fundamentais vão alicerçar definitivamente o Brasil que daí se constituiu. A condução da sociedade brasileira, totalmente "despreparada" para executar a tarefa grandiosa de ascensão do país somente poderia ser encaminhada pela elite intelectual verdadeiramente conhecedora da realidade nacional e preparada para conduzir a nação. Nesse sentido, as orientações presentes nos currículos de Geografia nas escolas vão se tornando cada vez mais condizentes com as necessidades brasileiras indicando uma reestruturação de ordem econômica indispensável para a consolidação da modernidade ensejada pelas classes econômicas à época.

A nacionalidade, discurso ideológico importante no ensino da Geografia serviu de ferramenta para a construção do território convergindo na direção de um projeto hegemônico de sociedade desejado pelas classes dominantes desde tempos pretéritos.

\section{REFERÊNCIAS}

ANSELMO, R.C.M.S. Geografia e geopolítica na formação nacional brasileira: Everardo Adolpho Backheuser. Tese (Doutorado em Geografia) - Rio Claro: IGCE - UNESP, 2000.

DALLABRIDA, N. A Reforma Francisco Campos e a modernização nacionalizada do ensino secundário. Educação, Porto Alegre, v. 32, n. 2, 2009. Pp. 185-191.

HERCULANO, E. O. Análise de compêndios de Geografia (1844 - 1890). Maceió, 2011. Trabalho de Conclusão de Curso. 90 p.

LACOSTE, Y. A geografia - isso serve, em primeiro lugar, para fazer a guerra. Campinas: Papirus, 2005.

MORAES, A. C. R. Bases da formação territorial: o território colonial brasileiro no "longo" século XVI. São Paulo: Hucitec, 2000.

MORAES, A. C. R. Território e História no Brasil. São Paulo: Anablume, 2005.

NAGAMINI, M. Ciência e Técnica na trilha da liberdade. In: MOTOYAMA, S. Prelúdio para uma história. Ciência e tecnologia no Brasil. São Paulo: EDUSP, 2004. Pp. 137-183.

PINHEIRO, A. C. Trajetória da pesquisa acadêmica sobre o ensino de Geografia no Brasil. 1972 - 2000. Tese (Doutorado em Geografia) - Campinas: Instituto de Geociências, UNICAMP, 2003. 
RIBEIRO JÚNIOR, J. O que é Positivismo. São Paulo: Brasiliense, 2006. Coleção primeiros passos.

ROCHA, G. O. R. Trajetória da disciplina Geografia no currículo escolar brasileiro (1837 1942). Dissertação (Mestrado em Geografia) - São Paulo: PUC, 1996.

SANTOS, E. S. Geografia escolar, pensamento geográfico e processos de recontextualização. Anais do XVI Encontro Nacional de Geógrafos. Porto Alegre, 2010. Pp. 1-12.

SANTOS, W. A obra de Aroldo de Azevedo - Uma avaliação. Instituto de Geociências e Ciências Exatas - UNESP. Rio Claro, 1984. 94 p.

SECO, A. P.; AMARAL, T. C. I. Marquês de Pombal e a reforma educacional brasileira. Grupo de Estudos e Pesquisas "História, Sociedade e Educação no Brasil". Faculdade de Educação - $\quad$ UNICAMP. 2006.2 Disponível em: http://www.histedbr.fe.unicamp.br/navegando/periodo_pombalino_intro.html. Acesso em: 07 de Abril de 2018. Pp. 1-11.

SOUSA NETO, M. F. O compendio elementar de Geographia Geral e Especial do Brasil. Terra Brasilis, Rio de Janeiro, v. 1, n. 1, 2000, p. 8-51. https://doi.org/10.4000/terrabrasilis.283

SOUZA, T. T.; PEZAATO, J. P. A geografia escolar no Brasil, de 1546 até a década de 1960. In: GODOY, P. R. T. (Org). História do Pensamento Geográfico e epistemologia em Geografia. São Paulo: Cultura Acadêmica, 2010, p. 71-90.

VLACH, Vânia R. F. O ensino de Geografia no Brasil: uma perspectiva histórica. In: VESENTINI, José W. (Org.). O ensino de Geografia no século XXI. 3a. ed. Campinas: Papirus, 2007, 187-218.

ZUSMAN, P.; PEREIRA, S. Entre a Ciência e a Política: um olhar sobre a geografia de Delgado de Carvalho. Terra Brasilis, Rio de Janeiro, v. 1, n. 1, 2000, p. 71-90. https://doi.org/10.4000/terrabrasilis.288

Recebido em: 27/09/2018

Aceito para publicação em: 10/01/2019 